\title{
Ulcerated Nodal Metastasis in Penile Carcinoma
}

\author{
Krishnamachar Harish*, Yagachikatte Chikkanarasaiah Madhu \\ Department Of Surgical Oncology, M S Ramaiah Curie Centre of Oncology, \\ M S Ramaiah Medical College, Bangalore, India \\ E-mail: ${ }^{2}$ rkhari@yahoo.com
}

Received May 5, 2011; revised June 16, 2011; accepted June 26, 2011

\begin{abstract}
A 35 year old male patient presented with untreated ulcerative lesion over the penis of one year duration with ulcerations over bilateral groin and suprapubic areas of three months duration. Biopsy was reported as squamous cell carcinoma. Involvement of nodes along suprapubic area is rare and is found ulcerated in this case. Ulceration of nodes and fixity occurs in the later stages of malignancy. Blowout of the underlying femoral vessels is one of the terminal events in such cases. This patient underwent bilateral ilioinguinal node dissection, total penoscrotal amputation and bilateral flap cover with tensor fascia lata flap.
\end{abstract}

Keywords: Penis, Carcinoma, Ulceration, Inguinal Nodes

\section{Introduction}

One of the most important determinants of outcome of penile cancer is the nodal disease. Palpable groin nodes are present in up to $60 \%$ of penile cancers and about $85 \%$ of these actually harbor metastatic disease [1,2]. The nodal disease progresses in a step wise manner from inguinal to pelvic and therapy of early nodal disease would be aimed at cure. We present an image of a locally advanced penile and groin lesions of carcinoma penis.

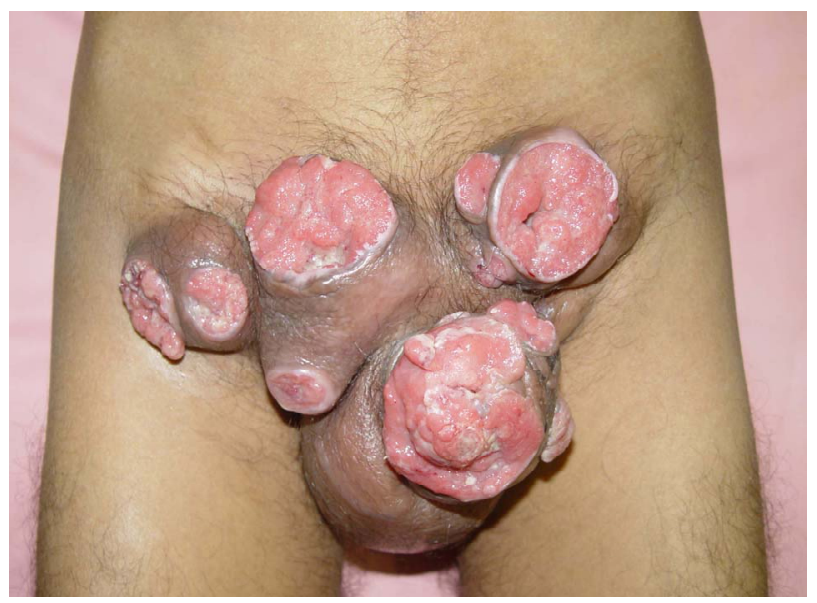

Figure 1. Clinical photograph showing primary ulceroproliferative lesion over the penis and ulceration over bilateral groin regions. Note that ulceration over the pubic symphysis area is the ulceration of rarely described nodes by Bazy and Decloux.

\section{Case Report}

A 35 year old male patient presented with untreated ulcerative lesion over the penis of one year duration, ulcerations over bilateral groin and suprapubic areas of three months duration. On examination, the ulcers have raised and everted edges with indurated base (Figure 1). Biopsy was reported as Grade 2 squamous cell carcinoma. CT scan revealed no involvement of deeper muscles or pelvic nodes (Figure 2). This patient underwent bilateral ilioinguinal node dissection, total penoscrotal

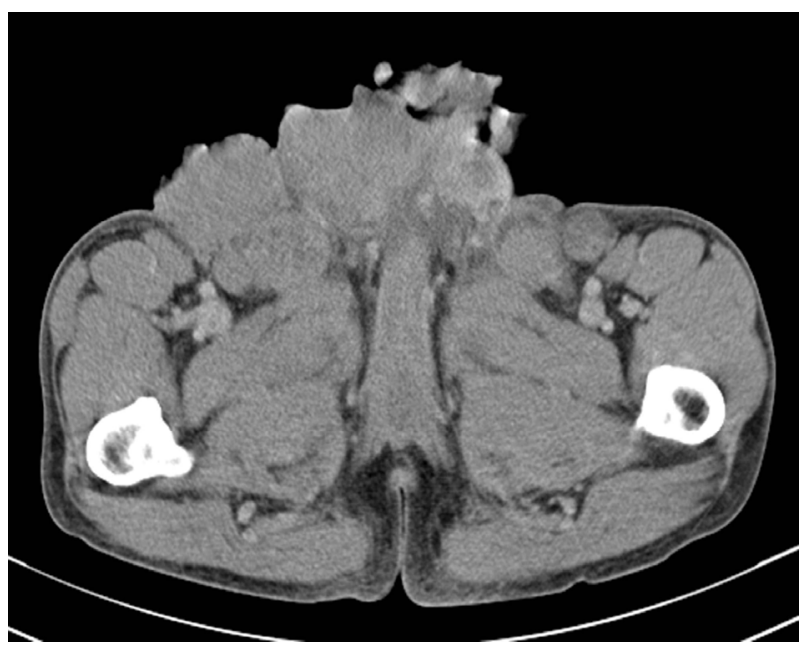

Figure 2. CT scan of groin area showing extensive nodal disease with skin involvement. Note that the deeper structures including vessels and muscles are free of disease. 
amputation and bilateral flap cover with tensor fascia lata flap for local control. He is being planned for adjuvant chemoradiation.

\section{Discussion}

Ulceration of nodes and fixity occurs in the later stages of malignancy. Blowout of the underlying femoral vessels is one of the terminal events in such cases $[3,4]$. There are some peculiarities in this patient. Bilateral inguinal nodes are involved with cutaneous ulceration. However neither underlying muscles nor pelvic nodes are involved. In addition, aberrant lymph nodes intercalated in the course of lymphatic trunks efferent to the inguinal nodes have been reported in the inguinal canal and over the symphysis pubis and at the base of penis $[5,6]$. Involvement of these nodes is extremely rare and is found ulcerated in this case. Based on retrospective studies [3,7-9] use of neo-adjuvant chemotherapy appears attractive. Increased disease control has been reported with adjuvant radiation in patients with bulky nodal disease [10]. However, in this case since nodes were not fixed to underlying structures and the fact that there were no radiologically detectable pelvic nodes, we opted for surgical resection with flap cover to be followed by chemoradiation. In addition, there are no prospective randomized trial results available at this time. Moreover, most of the studies address nodal disease after the primary has been treated. In this case, primary and nodal diseases were addressed simultaneously.

\section{References}

[1] S. Misra, A. Chaturvedi and N. C. Misra, "Penile Carcinoma: A Challenge for the Developing World," Lancet Oncology, Vol. 5, No. 4, 2004, pp. 240-247.

[2] V. Margulis and A. I. Sagalowsky, "Penile Cancer: Management of Regional Lymphatic Drainage,” Urologic Cli- nics of North American, Vol. 37, No. 3, 2010, pp. 411419. doi:10.1016/j.ucl.2010.04.009

[3] D. J. Culkin and T. M. Beer, "Advanced Penile Carcinoma,” The Journal of Urology, Vol. 170, No. 2 Pt 1, 2003, pp. 359-365.

[4] U. Ferreira, L. O. Reis, L. Y. Ikari, W. da Silva Jr., W. E. Matheus, F. Denardi, R. M. Stopiglia and F. H. Menezes, "Extra-Anatomical Transobturator Bypass Graft for Femoral Artery Involvement by Metastatic Carcinoma of the Penis: Report of Five Patients," World Journal of Urology, Vol. 26, No. 5, 2008, pp. 487-491. doi:10.1007/s00345-008-0282-z

[5] P. Bazy, “Ganglions du Penis,” In Gerota: Sur les Ganglions Prevesicaux. The Bullein of the Memebers of Surgical Society of Paris, Vol. 28, 1902, p. 538.

[6] L. Decloux, “Examen dún Ganglion Penien,” In Gerota: Sur les Ganglions Prevesicaux. The Bullein of the Memebers of Surgical Society of Paris, Vol. 28, 1902, p. 538.

[7] C. Bermejo, J. E. Busby, P. E. Spiess, L. Heller, L. C. Pagliaro and C. A. Pettaway, "Neoadjuvant Chemotherapy Followed by Aggressive Surgical Consolidation for Metastatic Penile Squamous Cell Carcinoma,” The Journal of Urology, Vol. 177, No. 4, 2007, pp. 1335-1338. doi:10.1016/j.juro.2006.11.038

[8] J. A. Leijte, J. M. Kerst, E. Bais, N. Antonini and S. Horenblas, "Neoadjuvant Chemotherapy in Advanced Penile Carcinoma,” European Urology, Vol. 52, No. 2, 2007, pp. 488-494. doi:10.1016/j.eururo.2007.02.006

[9] L. C. Pagliaro and J. Crook, "Multimodality Therapy in Penile Cancer: When and Which Treatments?" The Journal of Urology, Vol. 27, No. 2, 2009, pp. 221-225. doi:10.1007/s00345-008-0310-z

[10] M. F. Chen, W. C. Chen, C. T. Wu, C. K. Chuang, K. F. $\mathrm{Ng}$ and J. T. Chang, "Contemporary Management of Penile Cancer Including Surgery and Adjuvant Radiotherapy: An Experience in Taiwan,” The Journal of Urology, Vol. 22, No. 1, 2004, pp. 60-66. doi:10.1007/s00345-003-0383-7 